\title{
ANALISIS PERBANDINGAN KADAR TIMBAL (PB) DAN BESI (FE) DALAM DARAH PETUGAS PARKIR RUANG TERBUKA DENGAN RUANG TERTUTUP
}

\author{
Muhammad Nasir \\ Jurusan Analis Kesehatan Poltekkes Kemenkes Makassar \\ nasir@poltekkes-mks.ac.id
}

\begin{abstract}
ABSTRAK
Timbal $(\mathrm{Pb})$ dan Besi $(\mathrm{Fe})$ adalah unsur logam berat yang terdapat dalam kerak bumi, menyebar melalui aktivitas penambangan, kegiatan industri, emisi kendaraan dan sebagainya lalu masuk kedalam system biologi mahluk hidup. Paparan akan Timbal $(\mathrm{Pb})$ dan tidak dibanding dengan asupan zat Besi $(\mathrm{Fe})$ yang cukup dapat mengakibatkan munculnya bebrbagai penyakit kronis, seperti Epilepsi, halusinasi, Anemia Defisiensi Besi, dll. Pemeriksaan terhadap petugas parker dilatarbelakangi karena mereka salah satu bidang pekerjaan yang beresiko terhadap paparan logamberat. Pemeriksaan dilakukan dengan menggunakan alat SSA (Spektrofotometer Serapan Atom) guna mengetahui kadar paparan Timbal $(\mathrm{Pb})$ dan Besi $(\mathrm{Fe})$ dalam darah petuga sparkir yang nantinya akan dibandingkan antara petugas parker ruang terbuka dan ruang tertutup. Penelitian ini melalui tahap laboratory research dan menggunakan sebanyak 12 sampel (terbagi dua berdasarkan penempatan petugas parkir). Jenis penelitian ini yaitu adalah studi komparatif yang kemudian diolah dengan menggunakan uji statistic Uji T Dua Sampel Berbeda (Independent) dengan tingkat kemaknaan $\alpha=0,05$. Berdasarkan hasil uji statistic diperoleh kadar Timbal $(\mathrm{Pb})$ sebesar 0.587116173 dan kadar Besi (Fe) sebesar 0.25529958. Seluruh nilai statistic Sig. (2-tailed) > nilai kemaknaan antara petugas parker ruang terbuka dengan ruang tertutup, maka dapat ditarik kesimpulan bahwa tidak adanya perbandingan kadar Timbal $(\mathrm{Pb})$ dan Besi $(\mathrm{Fe})$ dalam darah petugas parker ruang terbuka dengan ruang tertutup.
\end{abstract}

Kata Kunci : Besi (Fe), Petugas Parkir, dan Timbal (Pb)

\section{PENDAHULUAN}

Telah banyak unsur kimia jenis logam berat yang telah teridentifikasi dimuka bumi ini. Berdasarkan sudut pandang toksikologi logam berat ini dapat dibagi dalam dua jenis. Jenis pertama adalah logam berat esensial, dimana keberadaanya dalam jumlah tertentu sangat dibutuhkan dalam organism hidup, namun dalam jumlah yang berlebihan dapat menimbulkan efek racun, seperti $\mathrm{Zn}, \mathrm{Cu}, \mathrm{Fe}, \mathrm{Co}$, $\mathrm{Mn}$, dsb. Sedangkan jenis kedua adalah logam berat tidak esensial atau beracun, dimana keberadaanya dalam tubuh masih belum diketahui manfaatnya atau bahkan dapat bersifat merugikan bagi tubuh, seperti $\mathrm{Hg}, \mathrm{Cd}, \mathrm{Pb}, \mathrm{Cr}$, dan lain - lain (Muh. Haris, 2015).

Salah satunya yang berbahaya bagi tubuh yaitu Timbal (Pb). Penyerapan $\mathrm{Pb}$ kedalam tubuh dapat melalui saluran pernapasan (pada alveolus), melalui kulit (apabila larut dalam lemak) dan saluran pencernaan 
dimana melalui minuman / makanan dan diserap oleh usus.

Khususnya udara yang tercemar mengandung logam-logam yang berbahaya sekitar kurang lebih $0,01 \%$ - 3\% dari seluruh partikulat debu yang tersebar di udara. Emisi timbal sebagai buangan dari kendaraan bermotor akan masuk ke udara dalam bentuk gas. Emisi timbal merupakan salah satu efek samping dari pembakaran yang terjadi dalam mesin kendaraan yang berasal dari senyawa Kimia Tetra Etil Lead dan Tetra Metil Lead yang ditambahkan dalam bahan bakar. $\mathrm{Pb}$ merupakan logam berat toksik hamper tanpa memiliki fungsi dan tidak diperlukan keberadaannya oleh tubuh (Palar, 2012).

Penggunaan bahan bakar seperti premium dan solar melepaskan 95\% emisi timbal yang dapat mencemari udara dan kemudian dapat dihirup serta diserap oleh tubuh sehingga menimbulkan gangguan kesehatan. Paparan akibat proses pembakaran bahan bakar dimesin kendaraan tentunya sangat akan berpengaruh terhadap para petugas parkir, bagian lapangan maupun bawah tanah.

Dalam reaksi metabolismenya dalam tubuh, $\mathrm{Pb}$ akan mengalir keberbagai organ (tergantung banyaknya aliran darah), seperti keotak, hati, kulit, ginjal dan muskulus skeletal.

Tetapi kadar timbal yang terdapat pada udara memiliki pengaruh yang besar terhadap kadar $\mathrm{Pb}$ dalam darah seseorang yang beraktivitas tinggi di jalanan, seperti pada petugas parkir. Kadar $\mathrm{Pb}$ dalam darah yang tinggi dapat mengganggu proses eritropoesis dan adanya gangguan sintesis heme yang diakibatkan oleh akumulasi $\mathrm{Pb}$ akan semakin buruk bila kecukupan zat besi tubuh tidak terpenuhi (Siwiendrayanti A., 2016).

Berdasarkan latar belakang diatas, maka telah dilakukan penelitian perbandingan kadar Timbal $(\mathrm{Pb})$ dan kadar Besi $(\mathrm{Fe})$ dalam darah petugas parke ruangan terbuka dengan ruangan tertutup.

\section{METODE}

Penelitian ini mengunakan jenis penelitian primer (memperoleh data dari sumber pertama), bersifat deskriptif komparatif (membandingkan dua atau lebih suatu fenomena), menggunakan pendekatan kuantitatif (pengembangan teori), serta ditindaki melalui laboratory research (pemeriksaan laboratorium).

Sampel yaitu petugas parkir yang dikelompokkan sesuai lahan bagian kerjanya (ruangan terbuka dan ruangan tertutup). Besar sampel sebanyak 12 sampel yang terdiri dari 6 sampel dari petugas parkir ruangan terbuka dan 6 sampel dari petugas parkir ruang tertutup dengan metode simple random sampling (acak, tanpa memperhatikan kriteria sampel).

Penelitian ini dilaksanakan di Laboratorium Kimia Kesehatan dan Lingkungan BBLK (Balai Besar Laboratorium Kesehatan) Makassar pada bulan Mei 2017.

Bahan penelitian ini yaitu sampel darah berjumlah 12 sampel, dengan rincian 6 sampel untuk pemeriksaan $\mathrm{Pb}$ dan 6 sampelnya lagi untuk pemeriksaan Fe. Asam Nitrat $\left(\mathrm{HNO}_{3}\right)$, Ferro Sulfat $\left(\mathrm{FeSO}_{4} .7 \mathrm{H}_{2} \mathrm{O}\right)$, Asam Sulfat $\left(\mathrm{H}_{2} \mathrm{SO}_{4}\right)$, Asam Perklorat $\left(\mathrm{HClO}_{4}\right)$ dan Amonium Tiosianat $\left(\mathrm{NH}_{4} \mathrm{SCN}\right)$ dan Timbal (II) Nitrat $\left(\mathrm{Pb}\left(\mathrm{NO}_{3}\right)_{2}\right)$ yang seluruhnya berkonsentrasi pekat, serta Aquades. Alat yaitu AAS (Atomic Absorbsion 
Spectroscopy), alat Erlenmeyer 10 dan $50 \mathrm{ml}$, Labu ukur 50 dan $100 \mathrm{ml}$, Hot plate, kertas saring Whatmann no. 41 , pipet pasteur, pipet ukur $5 \mathrm{ml}$, $10 \mathrm{ml}, 25 \mathrm{ml}$ dan $50 \mathrm{ml}$, serta timbangan analitik, corong gelas, kertas timbang, sendok kaca, penjepit tabung, kain pengalas dan Aluminium foil.

\section{Prosedur kerja}

Persiapan sampel

Persiapan larutan sampel melalui metode destruksi basah. 5 sampel dimasukkan kedalam erlenmeyer. Kemudian ditambahkan $15 \mathrm{ml} \mathrm{HNO}_{3}$ pekat, dihomogenkan. Dipanaskan perlahan-lahan hingga mendidih (sampai asap keluar sebanyak mungkin). Setelah itu didinginkan pada suhu ruang (untuk menghilangkan sisa uap asam). Kemudian ditambahkan aquades secukupnya lalu disaringkedalam labu ukur $25 \mathrm{ml}$ dengan menggunakan kertas saring whatman, larutan siap untuk dianalisis

Analisa kuantitatif kadar $\mathrm{Pb}$ dan $\mathrm{Fe}$

1. Pembuatan larutan baku induk $\mathrm{Pb}$ 1000 ppm

$\mathrm{Pb}\left(\mathrm{NO}_{3}\right)_{2} \quad$ ditimbang sebanyak 0,1599 g kemudian dimasukkan kedalam labu ukur $100 \mathrm{ml}$. selanjutnya dilarutkan dengan menggunakan $\mathrm{HNO}_{3}$ pekat sebanyak $7 \mathrm{ml}$. Setelah $\mathrm{Pb}\left(\mathrm{NO}_{3}\right)_{2}$ larut sempurna, ditambahkan (diencerkan) aquades dan dihomogenkan. Dilanjutkan dengan pembuatan larutan baku induk $100 \mathrm{ppm}$ dan 10 ppm, 5 ppm, 2 ppm, 1,5 ppm, $1 \mathrm{ppm}$ dan $0,1 \mathrm{ppm}$.
2. Pembuatan larutan baku induk $\mathrm{Fe}$ 1000 ppm ke 100 ppm dan 10 ppm $\mathrm{FeSO}_{4} .7 \mathrm{H}_{2} \mathrm{O}$ sebanyak 0,4978 g. dimasukkan kedalan labu ukur $100 \mathrm{ml}$. Dilarutkan dengan menggunakan $\mathrm{H}_{2} \mathrm{SO}_{4}$ pekat sebanyak $7 \mathrm{ml}$. Setelah $\mathrm{FeSO}_{4} .7 \mathrm{H}_{2} \mathrm{O}$ larut sempurna, ditambahkan (diencerkan) aquades hingga batas tara. Dilanjutkan dengan pembuatan larutan standar $100 \mathrm{ppm}, 6 \mathrm{ppm}, 5$ ppm, 4 ppm, 3 ppm, 2 ppm, 1,5 ppm, 1 ppm, 0,5 ppm dan 0,1 ppm.

Analisa data

Pada penelitian ini, data diperoleh dengan menggunakan persamaan regresi linear kemudian diolah dengan menggunakan persamaan uji t dua sampel berbeda (bebas) untuk membuktikan ada tidaknya perbandingan yang signifikan dari hasil penetapan kadar $\mathrm{Pb}$ dan Fe. Untuk memperoleh data dari alat AAS

\section{HASIL}

Diperoleh hasil penelitian terhadap kandungan Timbal $(\mathrm{Pb})$ dan Besi (Fe) pada darah petugas parker ruang terbuka dan ruang tertutup metode Spektrofotometri Serapan Atom (SSA).Ditunjukkan pada tabel 1. Tabel 1 merupakan hasil akhir perhitungan rumus untuk kandungan Timbal $(\mathrm{Pb})$ dan Besi (Fe) dalam sampel. 
Tabel 1 : Hasil akhir perhitungan rumus untuk kandungan Timbal $(\mathrm{Pb})$ dan Besi (Fe) dalam sampel.

\begin{tabular}{|c|c|c|c|c|c|}
\hline NO. & NO LAB. & $\begin{array}{c}\text { JENIS } \\
\text { SAMPEL }\end{array}$ & SATUAN & BESI (Fe) & $\begin{array}{c}\text { TIMBAL } \\
(\mathbf{P b})\end{array}$ \\
\hline 1. & 17108619 & $\mathrm{Fe} 01$ & \multirow{24}{*}{$\mathrm{mg} / \mathrm{l}$} & 710,16 & \\
\hline 2. & 17108620 & $\mathrm{Fe} 02$ & & 591,50 & \\
\hline 3. & 17108621 & $\mathrm{Fe} 03$ & & 500,20 & \\
\hline 4 & 17108622 & $\mathrm{Fe} 04$ & & 541,04 & \\
\hline 5. & 17108623 & $\mathrm{Fe} 05$ & & 520,23 & \\
\hline 6. & 17108624 & $\mathrm{Fe} 06$ & & 494,40 & \\
\hline 7. & 17108625 & $\mathrm{Fe} 07$ & & 384,90 & \\
\hline 8. & 17108626 & $\mathrm{Fe} 08$ & & 608,40 & \\
\hline 9. & 17108627 & $\mathrm{Fe} 09$ & & 488,55 & \\
\hline 10. & 17108628 & $\mathrm{Fe} 10$ & & 432,08 & \\
\hline 11. & 17108629 & Fe11 & & 506,05 & \\
\hline 12. & 17108630 & Fe12 & & 586,76 & \\
\hline 13. & 17108631 & $\mathrm{~Pb} 01$ & & & 0,229 \\
\hline 14. & 17108632 & $\mathrm{~Pb} 02$ & & & 0 \\
\hline 15. & 17108633 & $\mathrm{~Pb} 03$ & & & 0,046 \\
\hline 16. & 17108634 & $\mathrm{~Pb} 04$ & & & 0,137 \\
\hline 17. & 17108635 & $\mathrm{~Pb} 05$ & & & 0,266 \\
\hline 18. & 17108636 & $\mathrm{~Pb} 06$ & & & 0,412 \\
\hline 19. & 17108637 & $\mathrm{~Pb} 07$ & & & 0,305 \\
\hline 20. & 17108638 & $\mathrm{~Pb} 08$ & & & 0,046 \\
\hline 21. & 17108639 & $\mathrm{~Pb} 09$ & & & 0,228 \\
\hline 22. & 17108640 & $\mathrm{~Pb} 10$ & & & 0 \\
\hline 23. & 17108641 & $\mathrm{~Pb} 11$ & & & 0,4 \\
\hline 24. & 17108642 & $\mathrm{~Pb} 12$ & & & 0,381 \\
\hline
\end{tabular}

Berikut merupakan hasil pengukuran serapan larutan baku (nilai nilai tetap \&kurva) serta

kadar dalam bentuk telah dikonversi kesatuan nilai normal dalam darah :

Tabel 2 : Hasil pengukuran serapan larutan baku standar Timbal $(\mathrm{Pb})$ dengan Spektrofotometer Serapan Atom pada panjang gelombang $217 \mathrm{~nm}$.

\begin{tabular}{|c|c|c|c|}
\hline NO. & KODE SAMPEL & CONC. $\mathbf{( x )} \mathbf{~ p p m}$ & ABS $(\mathbf{y})$ \\
\hline 1. & BLK (Blanko) & 0,0586 & 0,0014 \\
\hline 2. & STD (Standar) 1 & 0,1000 & 0,0026 \\
\hline 3. & STD (Standar) 2 & 0,2000 & 0,0050 \\
\hline 4. & STD (Standar) 3 & 0,3000 & 0,0065 \\
\hline 5. & STD (Standar) 4 & 0,4000 & 0,0086 \\
\hline 6. & STD (Standar) 5 & 0,5000 & 0,0111 \\
\hline
\end{tabular}


Tabel 3. Hasil pengukuran serapan larutan baku standar Besi (Fe) dengan Spektrofotometer Serapan Atom pada panjang gelombang 248,3 nm.

\begin{tabular}{|c|c|c|c|}
\hline NO. & KODE SAMPEL & CONC. $(\mathbf{x}) \mathbf{p p m}$ & ABS (y) \\
\hline 1. & BLK (Blanko) & 0,0501 & 0,0031 \\
\hline 2. & STD (Standar) 1 & 0,1000 & 0,0111 \\
\hline 3. & STD (Standar) 2 & 0,2000 & 0,0510 \\
\hline 4. & STD (Standar) 3 & 1,0000 & 0,1040 \\
\hline 5. & STD (Standar) 4 & 1,5000 & 0,1621 \\
\hline 6. & STD (Standar) 5 & 2,0000 & 0,2045 \\
\hline
\end{tabular}

Tabel 4. Hasil analisis kandungan Timbal $(\mathrm{Pb})$ pada darah petugas parker ruang terbuka dan ruang tertutup.

\begin{tabular}{|c|c|c|c|c|c|}
\hline \multirow{2}{*}{$\begin{array}{c}\text { KODE } \\
\text { SAMPEL }\end{array}$} & \multirow{2}{*}{$\begin{array}{c}\text { PETUGAS } \\
\text { PARKIR }\end{array}$} & \multirow{2}{*}{$\begin{array}{l}\text { CONC. } \\
(\mathbf{x}) \text { ppm }\end{array}$} & \multirow{2}{*}{$\operatorname{ABS}(\mathbf{y})$} & \multicolumn{2}{|c|}{ KADAR TIMBAL (Pb) } \\
\hline & & & & $(\mathbf{p p m})$ & $(\mu \mathrm{g} / \mathrm{dl})$ \\
\hline $\mathrm{Pb} 01$ & \multirow{6}{*}{$\begin{array}{c}\text { RUANG } \\
\text { TERBUKA }\end{array}$} & 0,0815 & 0,0019 & 0,229 & 22,9 \\
\hline $\mathrm{Pb} 02$ & & $-0,0146$ & $-0,0002$ & $\begin{array}{c}-0,61 \\
(<0,01)\end{array}$ & $\begin{array}{c}-61 \\
(<0,01)\end{array}$ \\
\hline $\mathrm{Pb} 03$ & & 0,0632 & 0,0015 & 0,046 & 4,6 \\
\hline $\mathrm{Pb} 04$ & & 0,0723 & 0,0017 & 0,137 & 13,7 \\
\hline $\mathrm{Pb} 05$ & & 0,0906 & 0,0021 & 0,266 & 22,6 \\
\hline $\mathrm{Pb06}$ & & 0,0998 & 0,0023 & 0,412 & 41,2 \\
\hline $\mathrm{Pb} 07$ & \multirow{4}{*}{$\begin{array}{c}\text { RUANG } \\
\text { TERTUTUP }\end{array}$} & 0,0952 & 0,0022 & 0,305 & 30,5 \\
\hline $\mathrm{Pb} 08$ & & 0,0632 & 0,0015 & 0,046 & 4,6 \\
\hline $\mathrm{Pb} 09$ & & 0,0769 & 0,0018 & 0,228 & 22,8 \\
\hline $\mathrm{Pb} 10$ & & 0,0586 & 0,0014 & $0(<0,01)$ & $0(<0,01)$ \\
\hline $\mathrm{Pb} 11$ & & 0,0906 & 0,0021 & 0,4 & 40 \\
\hline $\mathrm{Pb} 12$ & & 0,1044 & 0,0024 & 0,381 & 38,1 \\
\hline
\end{tabular}

Berdasarkan hasil pemeriksaan kadar Timbal $(\mathrm{Pb})$, terdapat 2 sampel yang dapat dikatakan negative karena nilai hasil perhitungan rumus yaitu dibawah $<0,1 \mu \mathrm{g} / \mathrm{dldarah}$ 
Tabel 5 :Hasil analisis kandungan Besi (Fe) pada darah petugas parker ruang terbuka dan ruang tertutup.

\begin{tabular}{|c|c|c|c|c|c|}
\hline \multirow{2}{*}{$\begin{array}{c}\text { KODE } \\
\text { SAMPEL }\end{array}$} & \multirow{2}{*}{$\begin{array}{c}\text { PETUGAS } \\
\text { PARKIR }\end{array}$} & \multirow{2}{*}{$\begin{array}{l}\text { CONC. } \\
\text { (x) ppm }\end{array}$} & \multirow{2}{*}{$\operatorname{ABS}(\mathbf{y})$} & \multicolumn{2}{|c|}{ KADAR BESI (Fe) } \\
\hline & & & & (ppm) & $(\mathrm{mg} / \mathrm{ml})$ \\
\hline $\mathrm{Fe} 01$ & \multirow{6}{*}{$\begin{array}{c}\text { RUANG } \\
\text { TERBUKA }\end{array}$} & 1,8255 & 0,1908 & 710 & 0,71 \\
\hline $\mathrm{Fe} 02$ & & 1,8246 & 0,1907 & 591 & 0,591 \\
\hline $\mathrm{Fe} 03$ & & 1,3006 & 0,1353 & 500 & 0,5 \\
\hline $\mathrm{Fe} 04$ & & 1,4027 & 0,1461 & 541 & 0,541 \\
\hline $\mathrm{Fe} 05$ & & 1,6108 & 0,1681 & 520 & 0,52 \\
\hline $\mathrm{Fe} 06$ & & 1,5361 & 0,1602 & 495 & 0,495 \\
\hline $\mathrm{Fe} 07$ & \multirow{6}{*}{$\begin{array}{c}\text { RUANG } \\
\text { TERTUTUP }\end{array}$} & 1,2050 & 0,1252 & 385 & 0,385 \\
\hline $\mathrm{Fe} 08$ & & 1,5711 & 0,1639 & 608 & 0,608 \\
\hline $\mathrm{Fe} 09$ & & 1,0272 & 0,1064 & 488 & 0,488 \\
\hline $\mathrm{Fe} 10$ & & 1,1303 & 0,1173 & 432 & 0,432 \\
\hline Fe11 & & 1,0622 & 0,1101 & 506 & 0,506 \\
\hline $\mathrm{Fe} 12$ & & 1,8104 & 0,1892 & 587 & 0,587 \\
\hline
\end{tabular}

Berdasarkan hasil pemeriksaan kadar Besi (Fe), seluruh nilai hasil perhitungan rumus menunjukkan

\section{PEMBAHASAN}

Pada penelitian ini dilakukan analisis kandungan Timbal $(\mathrm{Pb})$ dan Besi (Fe) pada darah petugas parker ruang terbuka dan ruang tertutup metode Spektrofotometri Serapan Atom (SSA).

Analisis kandungan timbal $(\mathrm{Pb})$ dan Besi (Fe) didahului dengan proses preparasi sampel, pada proses preparasi sampel dilakukan proses dektruksi basah untuk menghasilkan larutan sampel. Dektruksi basah bertujuan untuk merombak logam seluruh sampel memiliki rata-rata kadar sebesar $0,501 \mathrm{mg} / \mathrm{ml}$ darah (telah dikonversid ari ppm).

organik yang terdapat dalam sampel dengan menggunakan asam kuat kemudian dioksidasi dengan menggunakan zatoksidator sehingga dihasilkan logam anorganik bebas yang kadarnya dapat diketahui dengan menggunakan Spektrofotometri Serapan Atom.

Pada proses dektruksibasah, sampel darah masing-masing diambil sebanyak $5 \mathrm{ml}$ kemudian ditambahkan larutan $\mathrm{HNO}_{3}$ pekat sebanyak $15 \mathrm{ml}$.Fungsi penambahan 
$\mathrm{HNO}_{3}$ ini adalah untuk dekstruksi atau memisahkan Timbal $(\mathrm{Pb})$ dan Besi (Fe) dari berbagai senyawa organic pada sampel darah. Senyawa timbal $(\mathrm{Pb})$ dan Besi (Fe) yang terpisah diikat oleh asam nitrat membentuk $\mathrm{Pb}$ nitrat dan Fenitrat sebagai senyawa yang mudah larut, sehingga nantinya dapat di tentukan kadar timbal $(\mathrm{Pb})$ dan Besi $(\mathrm{Fe})$ dalam sampel darah tersebut.

Setelah penambahan $\mathrm{HNO}_{3}$,sampel kemudian dipanaskan di atas hotplate secara perlahan-lahan sampai mendidih hingga asap berwarna kuning keluar sebanyak mungkin. Dilanjutkan dengan penambahan $15 \mathrm{ml} \mathrm{HNO}_{3}$ pekat dan dipanaskan lagi hingga seluruh bahan organik terbakar sampai asap putih keluar atau sampai larutan sampel berwana bening. Kemudian sampel didinginkan dengan tujuan agar semua gas $\mathrm{NO}_{2}$ hilang dan menguap. Lalu dilakukan penyaringan dengan menggunakan kertas Whatman no. 41 kedalam labu ukur $50 \mathrm{ml}$ dengan tujuan untuk menghilangkan sisa-sisa lemak danminyak yang dapat mengabsorbsi logam timbal $(\mathrm{Pb})$ danBesi (Fe) yang dianalisis. Setelah itu dicukupkan volumenya dengan air aquades hingga tanda batas $(25 \mathrm{ml})$, sehingga di dapatkan larutan hasil preparasi berwarna kuning jernih. Hasil larutan sampel tersebut selanjutnya diperiksa dengan alat Spektrofotometri Serapan Atom dengan panjang gelombang $217 \mathrm{~nm}$ untuk logam timbal $(\mathrm{Pb})$ dan panjang gelombang 248,3 nm untuk logam Besi(Fe).Spektrofotometri

merupakan analitik yang terutama sekali digunakan untuk analisis logam dalam jumlah yang sangat kecil karena sangat peka. Prinsip kerja alat ini adalah berdasarkan pada penguapan larutan sampel kemudian logam yang terkandung didalamnya diubah menjadi atom bebas. Atom tersebut mengabsorbsiradiasi dari sumber cahaya yang akan dipancarkan dari lampu katoda yang mengandung unsur yang akan ditentukan. Banyaknya penyerapan radiasi kemudian diukur pada panjang gelombang tertentu. Pada analisa kuantitatif, kadar unsure timbal $(\mathrm{Pb})$ dan Besi (Fe) dalam sampel diperoleh dari hasil ekstrapolasi serapan larutan sampel kedalam kurva standar, yaitu dengan jalan memasukkan serapan kedalam persamaan regresi yang di dapat. Dari persamaan regresi linear yang disajikan dalam grafik pada grafik 1 dangrafik 2 diperoleh nilai $r$ $=0,9963$ untuk timbal $(\mathrm{Pb})$ dan nilai $\mathrm{r}$ $=0,9988$ untuk Besi $(\mathrm{Fe})$, maka persamaan regresi linear tersebut digunakan sebagai perhitungan secara kuantitatif untuk memperoleh konsentrasi sampel dan selanjutnya dilakukan perhitungan untuk memperoleh kadar timbal $(\mathrm{Pb})$ dan Besi (Fe) bila terdapat dalam sampel. Penelitian ini menggunakan sampel darah dari partuga sparker ruang terbuka dan tuang tertutup. Sampel yang digunakan sebanyak 12 sampel yaitu terdiri dari 6 sampel darah dari partugas parker ruang terbuka dan 6 sampel darah lagi dari partugas parker ruang tertutup, untuk diperiksa kandungan timbal $(\mathrm{Pb})$ dan Besi $(\mathrm{Fe})$. Diperoleh hasil untuk kandungan Timbal $(\mathrm{Pb})$ pada sampel darah petugas parker ruang terbuka yaitu (tabel 4) bahwa rata-rata paparanTimbal sebesar 17,5 $\mu \mathrm{g} / \mathrm{dl}$ darah, sertaterdapat 1 sampel ( $\mathrm{Pb02})$ yang memilikinilaipaparanTimbal di bawah atau <0,01 dan dinyatakan negatif. Sedangkan untuk kandungan Besi ( $\mathrm{Fe}$, tabel 5), rata-rata kadar 
dalam sampel yaitu $0,5595 \mathrm{mg} / \mathrm{ml}$ darah. Untuk sampel darah petugas parker ruang tertutup yaitu (tabel 4) bahwa rata-rata paparan Timbal sebesar 22.66666667 $\mu \mathrm{g} / \mathrm{dl}$ darah, serta terdapat 1 sampel ( $\mathrm{Pb} 10)$ yang memiliki nilai paparan Timbal di bawah atau $<0,01$ dan dinyatakan negatif. Sedangkan untuk kandungan Besi (Fe, tabel 5), rata-rata kadar dalam sampel yaitu $0,501 \mathrm{mg} / \mathrm{ml}$ darah. Terdapat perbedaan kadar Timbal $(\mathrm{Pb})$ antara petugas parker ruang dan terbuka dengan nilai signifikan ( 2 jalur) yaitu 0.587116173 $(>0,05)$, sedangkan untuk kadar Besi (Fe) juga terdapat perbedaan dengan nilai signifikan (2 jalur) yaitu $0.25529958(>0,05)$.Toksisitas yang ditimbulkan oleh logam $\mathrm{Pb}$ dapat terjadi karena masuknya logam tersebut kedalam tubuh dapat melalui beberapa jalur salah satu diantaranya yaitu melalui pernapasan, buangan asap kendaraan biasanya mengandung Timbal $(\mathrm{Pb})$ dari proses pembakaran mesin.Walaupun kadar Timbal $(\mathrm{Pb})$ dalam bahan bakar kendaraan tidak melebihi dari nilai ambang yang diizinkan, tetapi senyawa $\mathrm{Pb}$ dapat menembus poripori kulit atau meresap dalam paruparu lalu masuk ke tubuh melalui aliran darah. Selanjutnya dikhawatirkan akan terjadi akumulasi kandungan Timbal $(\mathrm{Pb})$ karena masih banyak lagi kemungkinan Timbal $(\mathrm{Pb})$ dapat masuk selain asap buangan kendaraan, serta akan menyebabkan berbagai penyaki tdengan mengganggu berbagai system tubuh, seperti Epilepsi, halusinasi, menghambat pembuahan, anemia defisiensibesi, dll.

\section{KESIMPULAN}

Berdasarkan hasil penelitian didapatkan hasil yaitu :

1. Tidak adanya perbandingan kadar Timbal $(\mathrm{Pb})$ dalam darah petugas parker ruang terbuka dengan ruang tertutup.

2. Tidak adanya perbandingan kadar Besi $(\mathrm{Fe})$ dalam darah petugas parker ruang terbuka dengan ruang tertutup.

\section{SARAN}

1. Diharapkan calon peneliti selanjutnya dapat meneliti lebih lanjut terhadap unsur-unsur logam berat lainnya yang terdapat dalam darah selain Timbal $(\mathrm{Pb})$ dan Besi $(\mathrm{Fe})$, atau dapat melanjutkan penelitian ini karena melihat perkembangan kegiatan perusahaan penyedia / penyalur petugas parkir.

2. Kepada masyarakat, khususnya untuk perusahaan penyedia / penyalur petugas parker untuk senantiasa check-up kesehatan para karyawan dalam jangka waktu tertentu, untuk mengetahui apakah kadar logam berat dalam darah karyawan masih dalam ambangb atas normal dan beresiko menimbulkan penyakit atau tidak.

\section{DAFTAR PUSTAKA}

Anonim, 2011. AAS (Atomic Absorbsion Spectroscopy). http://teknologikimiaindustri. blogspot.co.id/spektrofotomet erserapan-atom-aas.html. Diakses pada tanggal 8 januari 2017.

Anonim,2016.

struksi. https://bisakimia.com/2016/0 5/09/destruksi/ Diakses pada tanggal 17 Januari 2017. 
Anonim, 2014. Pembahasan AAS atau Spektroskopi Serapan Atom.

https://bisakimia.com/2014/0

9/09/pembahasan-aas-atauspektroskopi-serapan-atom/ Diakses pada tanggal 17 Januari 2017.

Anonim, 2015. Toksikologi Teori. Makassar. Analis Kesehatan Poltekkes Kemenkes Makassar.

Effendi, F. dkk. 2012. Penyakit Akibat Kerja Karena Logam Berat. Jakarta :Direktorat Bina Kesehatan Kerjadan Olah raga Kementrian Kesehatan Republik Indonesia.

Gandjar, I.G., danRohman, A. 2007. Kimia Farmasi Analisis. Yogyakarta :PustakaPelajar.

Gusnita D. Pencemaran Logam Berat Timbal $(\mathrm{Pb})$ di Udara dan Upaya Penghapusan Bensin Bertimbal. LAPAN :Peneliti Bidang Komposisi Atmosfer.

Katzung B.G, Masters, B.S., Trevor J.A., 2012.

FarmakologiDasar\&Klinik. Jakarta : PT. RinekaCipta. Cetakan ke-2.
Kalma, dkk. 2015. Panduan PenulisanSkripsi. Makassar.

Kiswari R., 2014. Hematologi\&Transfusi. Jakarta :Erlangga.

Khopkar, S.M. 2003. KonsepDasar Kimia Analitik. Jakarta. UIPress.

Kurniawan W., 2008. Hubungan Kadar Pb Dalam Darah Dengan Profil Darah Pada Mekanik Kendaraan Bermotor Di Kota Pontianak. Semarang :Universitas Diponegoro.

Palar H., 2012. Pencemaran dan Toksikologi Logam Berat. Jakarta :RinekaCipta. Cetakan ke-5.

Puji M., 2010. Hubungan Antara Paparan Gas Buangan Kendaraan $(\mathrm{Pb})$ Dengan Kadar Hemoglobin Dan Eritrosit Berdasarkan Lama Kerja Pada Petugas Operator Wanita SPBU Di Wilayah Semarang Selatan. Universitas Muhammadiyah Semarang.

Ridhowati S., 2013. Mengenal Pencemaran Logam. Yogyakarta :Graha Ilmu. 